
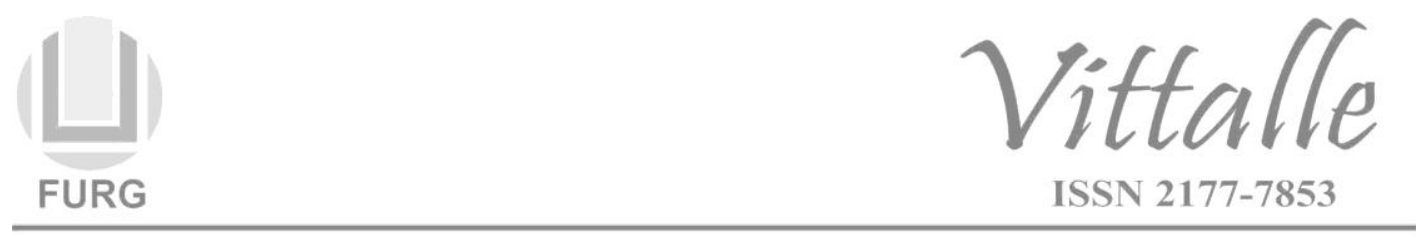

\title{
Cuidados com o recém-nascido: a contribuição do pai no aleitamento materno
}

\author{
Victoria Leslyê Rocha Gutmann ", Camila Daiane Silva, Ihana Arrieche Fazio, \\ Marina Soares Mota, Daniele Ferreira Acosta
}

Escola de Enfermagem, Universidade Federal do Rio Grande - FURG, Rio Grande, RS, Brasil

Histórico do Artigo
Recebido em
$09 / 04 / 2018$
Aceito em
$11 / 06 / 2018$

Palavras-chave:
Enfermagem;
Enfermagem
Obstétrica; Aleitamento
Materno; Pai; Cuidado
Pós-Natal; Paternidade;
Gestantes.

Keywords: Nursing; Obstetric Nursing; Breast Feeding; Fathers; Postnatal Care; Paternity; Pregnant Women.

\begin{abstract}
RESUMO
Objetivou-se identificar a contribuição do pai no aleitamento materno e nos cuidados com o recém-nascido. Trata-se de um estudo exploratório, descritivo, com abordagem qualitativa, realizado na maternidade de um Hospital Universitário no sul do Rio Grande do Sul. Coletaram-se os dados nos meses de agosto e outubro de 2016, através de entrevistas semiestruturadas, as quais foram tratadas pela Análise de Conteúdo. Participaram 30 pais. A análise dos dados resultou em três categorias: "As contribuições dos pais nos cuidados realizados quando o bebê chora", "As contribuições dos pais durante o aleitamento materno" e "As contribuições positivas que os pais acreditam que poderão realizar durante o aleitamento materno". A contribuição paterna nos cuidados com o bebê, durante o aleitamento materno, mostrou-se bastante ativa, estando a figura paterna incluída na vivência e responsabilização da paternidade.
\end{abstract}

Care with the newborn: the contribution of the father at the breastfeeding

\section{ABSTRACT}

The objective was to identify the father's participation in breastfeeding and care of the newborn. This is an exploratory, descriptive study with a qualitative approach, carried out in the maternity hospital of a University Hospital in the south of Rio Grande do Sul. Data were collected in August and October 2016, through a semi-structured interview, as which were handled by Content Analysis. 30 parents participated. The analysis resulted in three categories: "The father's contributions to baby crying", "The contributions of parents during breastfeeding" and "The positive contributions that parents believe they can make during breastfeeding." The paternal contribution to caring for the baby during breastfeeding was very active, with the inclusion of the father in the experience and accountability of paternity.

\section{Introdução}

O leite materno é a primeira prática alimentar a ser estimulada devido as suas propriedades de promover saúde e de prevenir diversas doenças (1), logo uma alimentação saudável se inicia com o Aleitamento Materno (AM). A amamentação é capaz de nutrir o bebê de modo adequado nos primeiros seis meses, tornando o leite materno exclusivo durante esse período, após, podem ser introduzidos alimentos complementares ao AM, por dois anos ou mais (2).

$\mathrm{O}$ aleitamento materno é preconizado por garantir numerosos benefícios para a criança, para a nutriz e seus familiares, bem como para a sociedade em geral. A composição imunológica e nutricional do leite materno proporciona ao bebê diversas vantagens. Entre elas, cita-se a prevenção de doenças como infecções, diarreias, alergias, doenças respiratórias, hipertensão, diabetes e obesidade (2). Além disso,

\footnotetext{
* Autor Correspondente: victorialeslye@gmail.com (Gutmann V. L. R.)
} 
promove melhor desenvolvimento da cavidade bucal, da fala e da cognição (3). Assim, por suas propriedades, a amamentação contribui para o crescimento e desenvolvimento adequado da criança.

Para a mulher, a amamentação favorece o vínculo afetivo, prevenindo a depressão pósparto e promovendo bem-estar e confiança na relação do binômio mãe-bebê (4). O aleitamento materno, a curto prazo, estimula a rápida recuperação na involução uterina e diminui a ocorrência de hemorragias após o parto, enquanto que, a longo prazo, contribui para menor incidência de determinadas patologias, como diabetes tipo 2, hipertensão, obesidade, osteoporose, câncer de mama, de ovário e de útero, entre outras (3).

Sabe-se que crianças não amamentadas são mais comumente afetadas por doenças, logo, com a realização do AM, a criança adoecerá menos e a família será pouco surpreendida com situações estressantes e gastos inesperados (2). Não apenas ocorre economia de recursos por menores gastos com a compra de fórmulas, mamadeiras ou medicações, como também de tempo, considerando que não há necessidade de preparo, aquecimento ou esterilização (4). Dessa forma, por ser uma prática alimentar simples, econômica e saudável é essencial que seja estimulada por todos as pessoas que cercam a nutriz.

A amamentação é fortemente influenciada pelo ambiente onde a lactante está inserida. Para um aleitamento bem-sucedido, a mulher necessita de apoio e incentivo dos profissionais de saúde, da sua família e da comunidade (2). A família representa a rede social primária dos indivíduos e possui a capacidade de cuidar e dar suporte aos seus membros, conforme seus valores, crenças e conhecimentos (5). No contexto familiar, o pai tem sido identificado como importante fonte de apoio à amamentação, tanto no incentivo do AM quanto na divisão de tarefas domésticas e de cuidados com o bebê $(2,6)$.

Com o processo de revolução industrial e a globalização, a mulher passa a se inserir no mercado de trabalho, começando a assumir múltiplos papeis no contexto familiar e social (7). A maternidade envolve uma série de mudanças na vida da mulher, como as alterações no corpo durante a gestação, parto e pós-parto, na rotina diária e nas dimensões sociais e laborais, compreendendo a prestação de cuidados ao novo membro da família. Dessa forma, a participação familiar, particularmente a do pai, torna essa experiência menos extenuante à mãe, a partir do momento em que ela percebe que pode contar com o apoio do parceiro, distribuindo tarefas, tensões, prazeres e as descobertas que envolvem esse momento.

Desse modo, além de contribuir com a parceira, a participação paterna promove o desenvolvimento e o crescimento saudável da criança, garantindo bem-estar e satisfação a todos os envolvidos. O pai se insere nos cuidados e aprende na medida em que pratica, descobrindo-se e construindo-se como pai. Ademais, sabe-se que o bebê, desde muito cedo, diferencia a figura paterna da materna e que a relação com o bebê traz benefícios à saúde mental da criança (8).

Torna-se importante romper com a figura do pai distante, autoritário e provedor financeiro, passando para um papel ativo. Para essa mudança de papel, é necessário que o homem seja instruído, recebendo informações dos profissionais da saúde, tal como a mulher. Dessa forma, os pais devem ser incluídos desde a gestação, pois, embora o homem não engravide fisiologicamente, a paternidade se inicia nessa fase (9). $O$ foco exclusivamente materno-infantil, que contribui para o afastamento do pai, deve ser superado pelos profissionais, centrando-se o enfoque na família. Assim, os pais devem ser inseridos nos cuidados com os filhos antes do nascimento desses, de modo que se preparem para exercer a paternidade e exerçam um maior cuidado com a mulher e o bebê (10).

Diante disso, verificou-se a necessidade de investigar: Qual a contribuição do pai no aleitamento materno e cuidados com o recém-nascido? Dessa forma, objetivou-se 
identificar os cuidados paternos com o recém-nascido e sua contribuição no aleitamento materno.

\section{Materiais e métodos}

Trata-se de um estudo exploratório, descritivo, com abordagem qualitativa realizado na maternidade de um Hospital Universitário no sul do Rio Grande do Sul, instituição certificada desde 2002 pela Iniciativa Hospital Amigo da Criança, que possui como objetivo oferecer todo o apoio ao aleitamento materno, conforme preconizado pela Organização Mundial da Saúde (OMS) e pelo Fundo das Nações Unidas para a Infância (UNICEF) (11).

A coleta de dados foi efetuada entre o mês de agosto e outubro de 2016. Realizou-se uma entrevista semiestruturada, a partir de um questionário elaborado, contendo perguntas relacionadas ao conhecimento do pai sobre o AM, sua participação nesse momento e as atividades desempenhadas por ele. Participaram 30 pais que preencheram os seguintes critérios de inclusão: ser pai de recém-nascido em alojamento conjunto na maternidade; estar acompanhando a mãe; ter idade igual ou superior a 18 anos. Foram excluídos os pais cujo recém-nascido estivesse internado na Unidade de Terapia Intensiva Neonatal e aqueles que a mãe recebeu o diagnóstico de HIV/AIDS ou apresentou outras impossibilidades de amamentar.

Os pais foram entrevistados em sala reservada, sem a interferência da mãe nas respostas, longe de ruídos ou intervenções. Foi utilizado um gravador e realizada a transcrição. Utilizou-se a Análise de Conteúdo, segundo Bardin (12), para o tratamento das entrevistas. Para garantir o anonimato, as falas dos participantes foram identificadas pela letra $\mathrm{P}$ (Pai) acrescida do número que identifica a ordem das entrevistas. O estudo foi aprovado pelo Comitê de Ética em Pesquisa da Área da Saúde (CEPAS) sob o Parecer $\mathrm{n}^{\circ}$ 71/2016 e CAAE 57572516.0.0000.5324.

\section{Resultados}

Participaram 30 pais, com idade variando de 18 a 50 anos, com predomínio para a faixa etária de 18 a 38 anos. Em relação à escolaridade, a maioria possuía o Ensino Médio completo/incompleto. No que se refere ao estado civil, a maioria morava com a companheira. A análise dos dados resultou nas seguintes categorias: "As contribuições dos pais nos cuidados realizados quando o bebê chora", "As contribuições dos pais durante o aleitamento materno" e "As contribuições positivas que os pais acreditam que poderão realizar durante o aleitamento materno". As duas primeiras categorias se referem às atividades já realizadas e mencionadas pelos pais. A última, porém, revela o que tais participantes pretendem vir a realizar de cuidados com o recém-nascido para, então, contribuir com o aleitamento materno.

\subsection{As contribuições dos pais nos cuidados realizados quando o bebê chora}

O choro é primordial para o bebê, pois é através dele que a comunicação com seus cuidadores se instala. Para alguns, principalmente os pais de primeiro filho, pode ser agoniante presenciar o choro. Frente a essa situação, alguns pais afirmaram que o cuidado prestado por eles é pegar o bebê no colo, outros é entregar imediatamente para a mãe e uns não conseguem agir. 


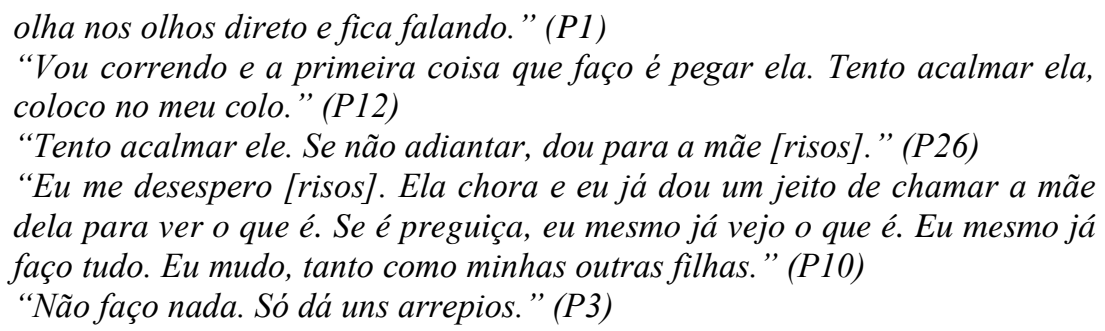

Por outro lado, alguns pais demonstraram um posicionamento diferenciado quando o choro é do seu filho. Ainda, a maioria acredita que o choro significa que o bebê está faminto.
"É engraçado. Até comentei com a minha esposa. Eu não gosto muito de bebê chorando, mas não era meu filho. Até então, não ser meu filho. Quando ela nasceu chorando, aquilo ali para mim... é como se ela estivesse conversando comigo. Não sentia essa rejeição, entendeu? [...] está sendo bom, maravilhoso." (P4)
"Quando ele chora, eu acho que é sinal que ele está com fome. Coloco no seio [da mãe] para ele mamar." (P28)

Porém, os pais reconheceram no choro outras necessidades dos bebês, além da fome.

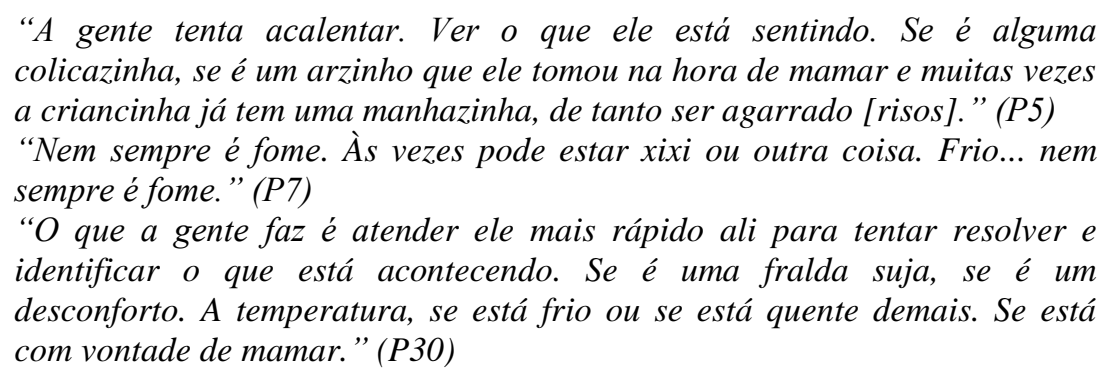

\subsection{As contribuições dos pais durante o aleitamento materno}

Apesar da ideia de que a principal forma de contribuir é financeiramente, os pais reconheceram diversas tarefas que realizam junto às mães para proporcionar um melhor desenvolvimento do AM, além de realizar cuidados com a própria puérpera.

\footnotetext{
"Eu acho que o pai ajuda é mais no dinheiro para comprar as coisas que precisa, tanto para o bebê quanto para a mãe. Depende de quantos meses ele tem... Hoje eu troquei a fralda, porque ela, no caso, ela foi de cesárea, ela não pode fazer. Quem leva ela nos compromissos dentro do hospital, tudo que precisa, sou eu." (P25)

"Eu ajudei ela... Tipo, como ela estava com os pontos, eu ajudei na movimentação, segurar o bebê direitinho. Ela estava ainda um pouco fraca." (P18)

"Alcanço o suco para ela, alcanço a água, muito eu fiz isso nessa noite. Trocava, alcançava para ela amamentar. Banho..." (P12)

"Por enquanto, eu não posso dizer nada porque recém faz dois dias. Vou tentar ajudar em tudo que puder. Dar a ela tudo que puder. Vou ajudar a cuidar, ajudar ela a comer, dar coisa boa para ela [...]. ” (P14)
}

O apoio emocional, incentivo e estímulo foram elencados pelos pais como suas contribuições para que a mãe consiga amamentar, tal como sua presença em diversos momentos que fazem parte do processo gestacional. Evidenciam que o esforço é 
recompensado pelos benefícios do AM ao bebê.

\begin{abstract}
"Eu tento ajudar. Estimular e apoiar a mãe. Sempre de maneira que ela consiga. Eu sei que não é fácil. Muitas vezes sente dor, sente desconforto ali e a gente tenta. Às vezes esses leites formulados são de alto custo [...] a questão nem é o valor que vai pagar, a questão é que o leite materno é mais saudável para ela [bebề].” (P2)

"Incentivando muito. Faz isso, faz aquilo, faz assim... No início, tu vai sentir dor provavelmente. Vai te cortar o seio, mas é... Precisa... é a melhor forma. Sempre dizendo... 'Ah, olha lá a criança que não mama e olha a nossa'. Nunca reclama que mama de mais ou mama de menos." (P10)

"Eu acho que ajudei conversando, estando do lado." (P24)

“Ah, tudo. Eu não saio do lado dela. Desde que engravidou [risos]. Fui em todas as consultas, fui em todo o pré-natal, em todos os examezinhos." (P29)
\end{abstract}

Ainda, a contribuição também ocorre no posicionamento da mãe e do bebê na amamentação e na busca por informações/conhecimentos corretos sobre o aleitamento.

\footnotetext{
“Ajeitei ela... Minha esposa a sentar, ajeitar o bebê, porque, às vezes, tem essa parte de achar uma posição, mas a bebê não ia e eu dava um empurrãozinho..." (P4)

"Hum, eu ajudei ela a pegar na mama da mãe dela. Ela não estava conseguindo pegar ainda." (P11)

"Eu também procurei me informar sobre. É que a minha primeira filha deixou de amamentar cedo. Por causa disso também. Deixava só pegar no bico, não pegava na aréola toda e aí começou a pisar a teta da mãe. Aí, consequentemente, não deu mais de amamentar. E só por causa da pegada. Então, dessa vez, nós já... por ter me informado.” (P23)
}

\title{
3.3 As contribuições positivas que os pais acreditam que poderão realizar durante o aleitamento materno
}

Com a chegada do novo integrante na família, os pais concordam que precisam desempenhar atividades para contribuir com o AM, compartilhando as responsabilidades com suas parceiras. Pretendem tanto realizar tarefas que estiverem ao seu alcance quanto cuidados mais específicos com o bebê e a mulher.

\footnotetext{
"O máximo, podendo auxiliar eu estou aqui na volta. Até no caso parei o serviço e estou aqui. Acho que já é o máximo que eu estou fazendo.” (P5)

"Ah, eu sou meio parado. O que me pedir para fazer eu faço. Do jeito que eu puder, eu ajudo." (P27)

"Acho que em tudo. Trocar o bebê, dar o banho, cuidar o umbiguinho." (P11)

“O que eu posso fazer mais... Trocar, mudar, vestir, dar banho." (P19)

"Ah, estar sempre observando ela e a criança. Cuidando os dois. No momento que ela dormir, alguma coisa, eu estou ali. Cuidando. Criança pequena a gente tem que estar com o olho aberto sempre. Uma vacilada, uma piscada de olhos... é uma complicação grande." (P14)

"Cuidando bem deles os três." (P17)
}

Para desempenhar tais funções, o pai acredita que o ambiente em que mãe e bebê estão inseridos deve estar de acordo com a tranquilidade que o momento da amamentação exige.

"Mais a questão do conforto. O que eu puder fazer mais para dar um conforto para as duas. Questão de ambiente... tentar deixar o ambiente mais 
calmo. Eu observei que teve duas noites que nós não tivemos acompanhante no quarto e que ela conseguiu amamentar melhor, teve uma noite melhor. A questão do ambiente é bem crucial." (P2)

"Tentar deixar o ambiente mais tranquilo. Evitar fazer barulhos. Deixar ela bem calminha, sem incomodar." (P4)

A participação do pai é importante no crescimento e desenvolvimento da criança. Assim, os pais se comprometem a permanecerem próximos, tornando-se exemplos e conquistando a admiração dos filhos. Porém, apesar dos esforços, as atividades laborais são citadas como um obstáculo para a realização de tal compromisso.

\footnotetext{
“Acho que o pai... Todo o pai tem que ser presente. Todas as horas possiveis com o filho.” (P25)

"Ah, eu acho que o pai tem que estar sempre presente. E quanto mais ele fizer ainda é pouco. Tem que estar sempre, até depois, maiorzinho. A presença do pai é muito importante. É importante para eles [filhos] e eles precisam. É uma referência para eles também." (P29)

"Ah, infelizmente o trabalho ocupa a gente fora de casa bastante tempo. Então, isso eu já estou prevendo é uma situação que... eu passo boa parte do dia fora. Por enquanto, ainda não vivenciei, mas já sei o que vai acontecer. Vou procurar, fora do horário de trabalho, ficar o mais próximo possível dela... é o que eu acho que é a maneira que eu posso colaborar." (P30)
}

Atrelado ao desafio de conciliar o trabalho com o novo membro da família, o pai entende que precisa realizar as atividades antes desempenhadas somente pela sua parceira, como os cuidados com a casa. Por fim, os pais reconhecem que precisam buscar por conhecimento, tanto para auxiliar a esposa como executar as atividades de cuidado com o bebê com maior segurança.

"Ah, eu teria que começar a ajudar mais minha esposa em casa. Até então, ela faz tudo, faz comida, lava roupa, arruma a casa e eu vou ter que ajudar ela." (P16)

"Estar mais presente com ela [mãe] em casa. Ajudar ela nas tarefas de casa também." (P12)

"Ah, eu acho que eu poderia correr mais atrás de informação para também ajudar ela." (P18)

"O que eu poderia ajudar mais... Sempre tem... Sempre dá de melhorar. Mas agora [...], recém nasceu minha segunda filha. Então, estou procurando fazer tudo do mais certo possível. A gente tem que correr atrás de informação para saber o que fazer de melhor. Às vezes, o cara acha que está fazendo certo, mas, às vezes, não é o certo. Então, tem que se informar para fazer direitinho, o correto." (P23)

\section{Discussão}

A comunicação do recém-nascido se dá por meio do choro. É por meio dele que o bebê alerta aos pais que alguma necessidade precisa ser suprida, como alimentação, hidratação, sono, repouso, segurança, amor e atenção. Assim, faz-se importante a ação dos cuidadores, de modo que a criança se sinta acolhida, protegida e com suas carências respondidas. Os participantes da pesquisa afirmaram que, frente ao choro, a primeira reação é pegar o bebê no colo e acalmá-lo, garantindo que a comunicação entre os cuidadores e o filho se concretize.

O choro também é uma considerável causa para o desmame, principalmente quando os pais e familiares se frustram ao manejá-lo, interpretando-o como fome e o leite materno como insuficiente. Alguns pais deste estudo identificaram o choro do bebê como sinal 
de fome, outros destacaram que significados diferentes também podem ser atribuídos. Assim, os participantes associaram o choro à presença de cólicas, gazes, necessidade de trocar a fralda e controle da temperatura corporal, identificando outras carências, além da fome. Cabe aos profissionais destacar as razões possíveis, esclarecendo que, muitas vezes, o recém-nascido se acalma ao ser confortado ou colocado no peito. Explicando também que, quando a mãe está tensa, frustrada ou ansiosa, pode transmitir esses sentimentos ao filho, causando mais choro (2).

Alguns pais afirmaram que a primeira reação frente ao choro é entregar o bebê para a mãe, o que dificulta sua inserção nos cuidados e responsabilidades com o filho. Logo, é fundamental que os pais consigam agir frente ao choro da criança, seja pegando-a no colo ou identificando e suprindo as suas necessidades. Ao assistir o recém-nascido, o homem estabelece estratégias de comunicação com o filho, as quais permitem ao bebê reconhecer o pai e esperar o acolhimento por parte dele também, fortalecendo o vínculo entre ambos (13). Assim, ao conseguir reconhecer desde cedo as carências do bebê, o pai se sentirá seguro para participar dos cuidados, aliviando, consequentemente, a tensão sobre a nutriz.

Os pais entendem que o ambiente em que a nutriz está inserida é crucial para o AM. Dessa forma, apontam como favorável contribuição o fornecimento de um ambiente tranquilo e confortável ao binômio mãe-bebê. Sabe-se que o ambiente em que a mulher se encontra e o apoio que ela recebe afetam diretamente a produção do leite materno, já que a ocitocina, hormônio liberado principalmente pelo estímulo da sucção da criança, também é disponibilizada em resposta a estímulos condicionados como a visão, cheiro e choro da criança, bem como a fatores de ordem emocional como motivação, autoconfiança e tranquilidade. Por outro lado, dor, desconforto, estresse, ansiedade, medo e insegurança podem inibir a liberação da ocitocina, prejudicando a saída do leite da mama (2).

Além de não sentir fisiologicamente a gestação, o homem não possui o conhecimento dos cuidados e tarefas quando comparado à mulher, a qual é preparada, desde a infância, por meio de brincadeiras ou na observação e repetição das ações de sua mãe (14), justificando como limitações sociais e culturais para a inserção do pai nos cuidados com os filhos. Porém, evidenciou-se nas falas dos pais a vasta participação paterna, superando a figura do pai provedor, autoritário e distante, admitindo-se um novo papel, presente e ativo. A figura paterna vem se transformando, passando a ser observada de forma qualitativa, não se preocupando somente com o suprimento material, mas também com sua participação na formação psicossocial da criança (15).

Nesse sentido, os pais relataram a participação efetiva em cuidados como troca de fraldas, banho e acompanhamento nos exames do recém-nascido no hospital. Eles afirmaram prestar apoio à companheira, tanto na sua movimentação quanto no posicionamento da mamada, principalmente quando em pós-cesárea, evidenciando a recuperação mais lenta da mulher após tal cirurgia. Destaca-se que os pais também contribuíram através do fornecimento de hidratação à puérpera, atitude importante dado o aumento da sede durante a amamentação (2).

Os participantes elencaram, ainda, como contribuição a sua presença nas consultas, exames e no pré-natal, demonstrando que sua participação deve ocorrer, preferencialmente, antes do nascimento. Ao se envolver no período gestacional, o homem se prepara tal qual sua companheira, corresponsabilizando-se pelos cuidados com o bebê (9). Também durante a gestação, os pais afirmaram que podem contribuir buscando informações. O conhecimento se faz importante, considerando que o ato de amamentar é um processo diferente a cada experiência e, por isso, sempre precisa ser ensinado, aprendido e reaprendido (16). 
Os pais afirmaram que, por meio do conhecimento, os desafios vivenciados em experiências anteriores podem ser superados, de modo a experenciar uma situação muito mais tranquila e prazerosa da amamentação. A informação se transforma em conhecimento e incentivo à mulher que amamenta, principalmente quando o pai reconhece a superioridade do leite materno sobre as fórmulas ou os leites de outras espécies (2). Um estudo com oito puérperas revelou que eram os companheiros que reforçavam a importância do aleitamento materno para a saúde da criança, mostrando-se incentivadores e apoiadores da amamentação (17).

Atividades semelhantes também foram observadas em um estudo no Paraná, com o objetivo de compreender a percepção de puérperas acerca da participação do companheiro nos cuidados prestados ao binômio mãe e filho, verificou-se a participação paterna como fonte de satisfação para a mulher e também para o próprio pai (18). Assim, os pais podem influenciar as mães, seja simplesmente com sua presença ou na transmissão de informações e apoio, reconhecendo as dificuldades, porém exaltando os benefícios que a amamentação proporciona.

Durante a amamentação, é exaustivo para a mulher cuidar do bebê, uma situação nova mesmo que ela já tenha filhos. Quando a mulher precisa cuidar da casa e de outros filhos, ela acaba se vendo sobrecarregada e a dedicação necessária ao lactente é reduzida (2). Por isso, é fundamental a presença do companheiro na divisão das atividades domésticas e no cuidado com os filhos mais velhos, para que a mulher não veja nas mamadeiras ou em outros utensílios artificiais uma maneira "prática" de alimentar seu bebê, enquanto ela cuida de outros afazeres e, com isso, resulte no desmame por sobrecarga materna.

A família, em especial o companheiro, pode contribuir para a prevenção do desmame precoce. A contribuição pode vir através da busca por informação, divisão de tarefas e até mesmo o não oferecimento de produtos que prejudicam a amamentação, como latas de leite, mamadeiras e chupetas (2). Assim, os pais entrevistados demonstraram que precisam estar mais presentes, realizando cuidados com o bebê e com a parceira, além de dividir as tarefas e responsabilidades de casa e educação dos filhos. Além disso, os pais reconheceram as contribuições com as tarefas do lar como uma atividade nova, até então desempenhada somente pela sua parceira. Isso demonstra que o homem vê a puérpera e suas necessidades, sensibilizando-se a mudar de papel e assumir uma posição mais ativa, demonstrando que a participação do pai é passível de ser construída (10).

Ressalta-se a importância do companheiro com sua presença e participação, considerando que, muitas vezes, ele é a única ou a principal referência da mulher em seu contexto domiciliar, configurando-se como aquele com quem ela poderá contar para realizar os cuidados com ela e com o bebê (10). A presença é destacada pelos próprios pais participantes deste estudo como uma contribuição relevante e uma fonte de admiração para os filhos. Porém, as atividades laborais deles se tornam um obstáculo, tornando difícil conciliar o horário de trabalho com a divisão das tarefas do lar e os cuidados com a criança.

Atualmente, a licença paternidade pode ser prolongada até 20 dias se a empresa for vinculada ao Programa Empresa Cidadã (19), caso contrário, o homem terá direito a cinco dias. Com isso, a participação paterna é reduzida devido a sua carga horária, enquanto que sua parceira precisará despender do seu tempo para além dos cuidados com a criança, também com os cuidados com a casa, caracterizando uma jornada múltipla, mesmo durante o período de licença maternidade.

Mesmo diante das dificuldades em ser e estar presente, o pai assume uma postura mais igualitária perante sua companheira ao adquirir maior consciência sobre a sua importância no ambiente familiar (10). A postura igualitária surge quando o homem se 
mostra disponível tanto para cuidar do bebê quanto para realizar as tarefas domésticas, contribuindo para prevenir o desgaste da mulher e para promover o vínculo familiar (10). Assim, as atividades desempenhadas pelo pai repercutem em consequências positivas para sua companheira, para si próprio e para o desenvolvimento e crescimento saudável da criança (2).

A construção do pai participativo se dá também pela busca de conhecimento, pois supõe-se que, quando informado, o homem torna-se melhor preparado a assumir funções. Nesse momento, surge a Enfermagem e o seu papel na educação e promoção em saúde. $\mathrm{O}$ enfermeiro surge como facilitador do processo gravídico-puerperal e um integrante da rede de apoio ao casal, estando presente no planejamento familiar, prénatal, grupo de gestantes, parto, puerpério, visitas domiciliares, puericultura e em outros momentos oportunos para a disseminação de informações que poderão garantir para a lactante, bebê e seus familiares uma vivência prazerosa da amamentação.

\section{Considerações finais}

A contribuição paterna se mostrou ativa e positiva no aleitamento materno e nos cuidados ao recém-nascido. Os pais demonstraram assumir diversas funções no cuidado com os filhos, inclusive ao choro do bebê, momento em que há maior tensão e sentimento de impotência em não conseguir acalmá-lo. Nessa situação, a maioria se mostrou capaz de agir, pediriam auxílio à mulher caso não conseguissem manejar e outros entregariam o bebê de imediato. Além disso, o choro foi identificado por muitos pais como indicativo de fome, mas também há aqueles que, primeiramente, procuram por outras causas.

Muitas foram as contribuições citadas pelo pai, destacando-se a ideia ainda presente sobre o papel provedor que o homem possui na criação dos filhos. Entretanto, foram reveladas outras ações como os cuidados com o bebê na troca de fraldas e banho, bem como com a puérpera, auxiliando na movimentação e posicionamento dela, mas principalmente na presença e na verbalização do apoio e incentivo ao AM. A busca por informações também se destaca como forte contribuição para a amamentação. As contribuições futuras citadas envolvem os cuidados com o bebê e a companheira, a garantia de um ambiente favorável, a divisão de tarefas e a presença em si, as quais encontram barreira devido à carga horária de trabalho.

Por fim, admite-se como limitações na realização do estudo, os poucos pais presentes durante a internação pós-parto e o fato de ser um estudo realizado em apenas um contexto. No entanto, acredita-se que o estudo possibilitou a compreensão da contribuição paterna nos cuidados com o recém-nascido e no aleitamento materno, verificando-se a importância da inserção e da corresponsabilização junto à mãe. Assim, recomenda-se para futuras pesquisas a ampliação do estudo para além do ambiente hospitalar, identificando, também, a percepção das puérperas sobre a participação do parceiro.

\section{Referências}

1. Ministério da Saúde [Internet]. Saúde da criança: nutrição infantil. Brasília, DF: 2009. [citado em 2018 Feb 15]. $\quad$ Disponível em http://bvsms.saude.gov.br/bvs/publicacoes/saude_crianca_nutricao_aleitamento_alimentacao.pdf

2. Ministério da Saúde [Internet]. Saúde da criança: aleitamento materno e alimentação complementar. Brasília, DF: 2015. [citado em 2018 Feb 11]. Disponível em http://bvsms.saude.gov.br/bvs/publicacoes/saude_crianca_aleitamento_materno_cab23.pdf

3. Martins MZO, Santana LS. Benefícios da amamentação para saúde materna. Interfaces Científicas Saúde e Ambiente 2013;1(3):87-97. 
4. Oliveira CM, Santos TC, Melo IM, Aguiar DT, Netto JJM. Promoção do aleitamento materno: intervenção educativa no âmbito da Estratégia de Saúde da Família. Enfermagem Revista 2017;20(2):99-108.

5. Prates LA, Schmalfuss JM, Lipinski JM. Amamentação: a influência familiar e o papel dos profissionais de saúde. Revista de Enfermagem da UFSM 2014;4(2):359-367.

6. Lima FA. Aleitamento materno: qual o conhecimento do pai e seu papel na amamentação? Salvador. Monografia [Graduação em Medicina] - Universidade Federal da Bahia; 2014.

7. Anais da $1^{\text {a }}$ Semana de Enfermagem da Faculdade do Vale do Juruena; 2015 maio 13-15; Mato Grosso, Brasil.

8. Moraes CJA, Granato TMM. Tornando-se pai: uma revisão integrativa da literatura sobre a transição para a paternidade. Psicologia em Estudo. 2016;21(4):557-567.

9. Barbosa NR, Almeida MS, Coelho EAC, Oliveira JF. Da gestação ao nascimento: percepção do casal grávido. Revista Baiana de Enfermagem. 2013;27(2):108-123.

10. Henz GS, Medeiros CRG, Salvadori M. A inclusão paterna durante o pré-natal. Revista de Enfermagem e Atenção à Saúde. 2017;6(1):52-66.

11. Ministério da Saúde [Internet]. Iniciativa Hospital Amigo da Criança. Brasília, DF: 2009. [citado em 2018 Jan 29]. Diponível em http://bvsms.saude.gov.br/bvs/publicacoes/iniciativa_hospital_amigo_crianca_modulo3.pdf8

12. Bardin L. Análise de Conteúdo. Lisboa: Edições 70; 2011.

13. Matos MG, Magalhães AS, Féres-Carneiro T, Machado RN. Construindo o vínculo pai-bebê: a experiência dos pais. Psico-USF 2017;22(2):261-271.

14. Ribeiro JP, Gomes GC, Tarouco BS, Cardoso LS, Silva PA, Strefling ISS. Participação do pai na gestação, parto e puerpério: refletindo as interfaces da assistência de enfermagem. Revista Espaço para a Saúde 2015;16(3):73-82.

15. Resende TC, Dias EP, Cunha CMC, Mendonça GS, Ribeiro ABJ, Santos LRL, Silva EP. Participação paterna no período da amamentação: importância e contribuição. Bioscience Journal 2014;30(3):925-932.

16. Prates LA, Schmalfuss JM, Lipinski JM. Problemas e condutas adotadas por puérperas durante a lactação. Revista de Enfermagem UFPE 2015;9(2):500-508.

17. Silva CMS, Bortoli CFC, Massafera GI, Silverio M, Bisognin P, Prates LA. Sentimentos e vivências maternas associadas ao processo de amamentação. Revista de Enfermagem UFPE 2015;9(8):93439351.

18. Silva EM, Marcolino E, Ganassin GS, Santos AL, Marcon SS. Participação do companheiro nos cuidados do binômio mãe e filho: percepção de puérperas. Revista de Pesquisa Cuidado é Fundamental Online 2016;8(1):3991-4003.

19. Brasil. Lei $n^{\circ} .13257$, de 8 de março de 2016. Dispõe sobre as políticas públicas para a primeira infância. Diário Oficial da União 9 mar 2016. 